\title{
The Aesthetic and Plastic Values for the Concept of Synthesis through the Ages and the Variables of Material and Designing the Hanging Textile
}

\author{
By Nahla Ahmed Hamdy El-Deeb ${ }^{1}$
}

\begin{abstract}
Synthesis means intermarriage and compatibility between more than one raw material in a single artwork. Interacting with its various properties and sources to reach a balance between expressive and technical aspects within the framework of the technical and technical capabilities of that raw material. By adding raw materials, they are woven with textured structures or by the new method developed through the art of gluing or collage and the art of assembly through deletion and addition within the scope of plastic treatments of the textile surface or by using both the traditional and the new method combined to merge between Woven materials and added media on the surface of the artwork. The research deals with synthesis through the ages (the ancient Egyptian - Coptic - Islamic - popular) and some schools of modern art (Cubism - Dada - Pop Art) and some pioneers in plastic art in Egypt (Munir Kanaan - Ahmed Nawar - Farghali Abdul Hafeez - Zainab Sabra).

Research Problem: - To what extent can the aesthetic and plastic values be benefited from the different treatments of natural and synthetic textile materials for the concept of synthesis?

Research Aims: - Revealing the aesthetic, plastic, and artistic values of the synthesis method throughout the ages to find new approaches to teaching manual fabric. - Create innovative aesthetic values and formulations on the surface of the tissue sphere. The current research provides a program consisting of 3 teaching entrances that depend on a number of key and sub-concepts proposed for the concept of synthesis through art education.
\end{abstract}

Keywords: The Aesthetic - Plastic Values - The Concept of Synthesis - V ariables of Material and designing Hanging Textile

\section{Research Background}

Synthesis is an attempt to find compatibility between more than one of its raw materials in artistic expression, whereby the materials collectively enrich the artistic work itself ... In the Department of Art Knowledge, "the definition of synthesis came in a more general way, on the basis that it uses different raw materials from scraps and wastes from the point of view of the plastic value or The texture, color, or value of the shape itself, and the synthesis materials may deal with their representative value, that is, as they are shapes or objects that indicate meanings, and call for correlative values, depending on the suitability of the materials with each other and the artist's thought and provoke it from the reaction of the viewer. $(18$ - 316).

"And the synthesis between more than one material that meets one artistic work is that the outcome of the interaction of multiple materials with different sources so that the practical aspects and aesthetic values are balanced within the framework of the natural 
capabilities and limits of these raw materials, whether they are technical or technical" (1023).

The material and its association with technology differ in techniques and vary with each raw material, so there is a diversity in the formal appearance of the material. "Techniques that define expressive values are defined and the technology is related to the synthetic properties of the material. It is the medium and the formative approach that the artist deliberately intends to adapt his materials and subject them to the creative process to achieve his artistic work. And due to his experience and the extent of his ability to deal with it, experimentation and innovation within the technical workshops, it is considered one of the primary tasks of the artist to get acquainted with its use and its method of operation in light of the huge technological progress. " (4- 34).

The material and its association with plastic values are related to judging the value in the work of art to the extent of the artist's ability to the provisions of its formulation and the use of an appropriate technical method that interacts with the material with its formative and expressive capabilities and the formative values are produced through the foundations upon which the artist relies on formulating the plastic elements of points, line, area, color, texture and others to achieve alone A variety of values of balance, movement, depth, and space. "The value of the artwork is inferred by an evaluation of the characteristics represented in its material construction consisting of raw material and shape as a product of the creative process carried out by the artist" (15-88).

The use of raw materials and their association with aesthetic values. Beauty is an objective reality that exists in an environment with certain conditions through which you realize, for this the concepts of beauty have been formed throughout the ages by changing environmental and aesthetic conditions. Philosophically, humanitarian concepts share a vision and understanding of the laws of art and standards for judging artwork in a given period of time "(8-113).

\subsection{Research Problem}

Based on the above, the research problem may be determined in the following question: To what extent can the aesthetic and plastic values be benefited from the different treatments of natural and synthetic textile materials for the concept of synthesis?

\subsection{Research Imposition}

There is a positive relationship between the aesthetic and plastic values of the different treatments of textile materials for the concept of synthesis and the enrichment of tissue suspensions of students of the Faculty of Art and Design.

\subsection{Research Aims}

1. Revealing the aesthetic, formal and artistic values of the synthesis method throughout the ages to find new approaches to teaching manual fabric.

2. Production of textile suspensions based on extracting experimental approaches based on aesthetic and plastic relations between the used textile techniques and homogenous materials for the synthesis between the variable of the material and the design. 


\subsection{Research Importance}

1. Shed light on the role of different treatments of textile materials (natural / silent) and the synthesis between the materials and design variables and their effect on tissue formation.

2. Benefiting from the synthesis of more than one artistic field as a new experimental approach to achieve an innovative vision in hand-woven textiles.

\subsection{Search Limits}

1. A program consisting of 3 teaching entrances based on the concept of synthesis, an introduction to each idea.

2. Implementing the experiment on the fourth group, Fashion Design Department, Faculty of Arts and Design, Pharos University in Alexandria.

3. The idea of experiment takes 15 weeks, with a duration of 5 hours per lecture, through the course of the art of synthesis of materials, code number FD511 through which to explain (the idea, design, implementation).

4. Materials are used from Canson paper, newspapers, magazines, sisal and jute ropes, beads, tulle and lace fabrics, metal wires, some prefabricated wood pieces.

5. Tissue structures used as $1 / 1$ plain, simple files, monotype printing, some types of embroidery stitches.

\subsection{Search Terms}

Aesthetic values: "Values and models by which artworks are measured, such as the relationships between shapes, color harmonies, composition balance, and others." (6286).

Formative values: "It is a group of material organizational relationships that can be measured because of its direct association with the formulation of form and material and what it reflects from the values that achieve the work alone and what is consistent with its content" (2-4).

Synthesis: "The process of unifying, combining, or combining between a different group that can be composed from a specific number." (11-6). "The word Elias indicates that the word synthesis means pasting or combining different things or a variety or formative group from different" (16-100). As for the glossary of art and artists, the word synthesis is used in the sense of "a picture that is fully or partially established using scraps of fabric, paper, or the like, from the materials that are affixed on the canvas or on any other ground" (17-89).

\section{Research Methodology}

First: Theoretical Framework: The researcher follows the descriptive historical analytical method:

1. A historical monitoring of the concept of synthesis through the ages (the ancient Egyptian - Coptic - Islamic - folk - modern art).

2. It follows the role of the material and its correlation with aesthetic, plastic, and technical values. 
3. A historical study of the artwork based on the synthesis.

Second: The Practical Framework: The researcher follows the experimental approach through several practical applications:

Design a proposed program entitled: (Aesthetic and plastic values of the concept of synthesis across the ages, material variables and design in the textile suspension) and a program consisting of three teaching approaches is applied that depend on a number of key and sub-concepts proposed for the synthesis concept.

The target sample: Fourth year students - Fashion Design Department - for the academic year fall 2019/2020.

Place of the program: Faculty of Art and Design - Pharos University in Alexandria.

Program time: Fifteen weeks with 5 hours of lecture, one credit hour is counted.

And that is through the course of the art of synthesis of raw materials, code No. FD511

This course aims to study the concept of synthesis, whether with natural or industrial raw materials or consumables of a nature of use and the interpretation of its implications, whether in the field of clothing supplements or artistic works in the light of the available techniques and the application procedure, which contributes to deepening the practice Regulations (College of Art and Design).

The course of the program: These stages play reciprocal roles that affect each other through feedback, a progressive evaluation after each lecture and a final evaluation after the end of the teaching program.

\begin{tabular}{|c|c|c|c|}
\hline No & The Stages of the Program & $\begin{array}{c}\text { Number of } \\
\text { Lectures }\end{array}$ & Hours. \\
\hline $1-$ & The idea & $1 \mathrm{st}, 2 \mathrm{nd}$ & 10 \\
\hline $2-$ & Design & 3rd & 5 \\
\hline \multirow{3}{*}{ 3- } & $\begin{array}{l}\text { The First Entry: technical and aesthetic values between the } \\
\text { synthesis of environmental materials and the concept of collage } \\
\text { and its effect on weaving }\end{array}$ & $\begin{array}{l}\text { 4th, 5th, } \\
\text { 6th, 7th }\end{array}$ & 20 \\
\hline & \begin{tabular}{|ll}
$\underbrace{}_{\mathscr{W}}$ & The Second Entry: Plastic data for the synthesis between raw \\
material, printing effects, textile and embroidery
\end{tabular} & $\begin{array}{c}\text { 8th, 9th, } \\
10 \text { th, 11th }\end{array}$ & 20 \\
\hline & The Third Entry: Forming variables for geometric solids & $\begin{array}{l}\text { 12th, 13th, } \\
14 \mathrm{th}, 15 \mathrm{th}\end{array}$ & 20 \\
\hline Total & & $\begin{array}{c}15 \\
\text { Lectures }\end{array}$ & $\begin{array}{c}75 \\
\text { Hrs. }\end{array}$ \\
\hline
\end{tabular}

Program Objectives: The student should be able to:

\section{Information and Concepts:}

1. Mention the most important environmental materials and the formation of textiles.

2. Choose a method of synthesis with materials, and the effect of that on technical and aesthetic values.

3. Mentions the aesthetics of collage formation methods in schools of modern art.

4. It connects the concept of raw material and technology with its effect on the aesthetic, plastic and expressive.

\section{Mental Skills:}

1. He contrasts schools of modern art (cubism - futurism - Dada - surrealism - Bauhaus - 
abstract expressionism - pop art - the art of visual deception - contemporary art - ...) in choosing the idea of design.

2. It reveals the relationship between monitoring the formal capabilities of printing techniques from (slide - spray - spray - silk screen - direct drawing - pouring - monotype - ...).

3. Organizes the relationship between the methods of embossing, weaving, embroidery and printing inside the art.

4. It solves the difficulties and problems it faces while designing the artwork.

Professional Skills:

1. He selects a set of artistic designs that illustrate the aesthetics of collage formation methods in schools of modern art.

2. The synthesis between collage, textile and printing capabilities.

3. Discover a set of structural relationships from (delete or add) - (enlarge or reduce) (contact or overlap) to create a woven artwork.

4. It links the principles of modern art schools with the development of collage techniques.

\section{General Skills:}

1. The environment considers the decorative artwork as a creative artwork.

2. Evaluating risks and working under pressure to solve technical problems and obstacles that face it during technical work.

3. Uses the Internet to find out what's new in the field of artistic design.

4. Offers alternatives to solutions in light of a set of technical foundations and standards.

\section{Program Progress}

\subsection{The first and Second Lecture: (The Idea)}

Aesthetic approaches to handling raw materials and their synthesis in handwoven textures, "The aesthetic concept of raw material handling and the formative thought that the artist deals with in order to construct the artwork, achieving compatibility between the intellectual, plastic, and technical content of the work that shows the aesthetic and plastic values" (7-6).

And "the mixing of the textile materials and other materials, whether processed or untreated, on the surface of the tissue hangers, is achieved through: the traditional method in terms of adding the materials by weaving them with textile structures and techniques. As for the new method, combining more than one direction in the textile suspension such as collage, collage, art, Assembling is a third method that combines the traditional and novel method as a method of combining textile materials with other additives added on the surface of the fabric suspensions "(3-102). 

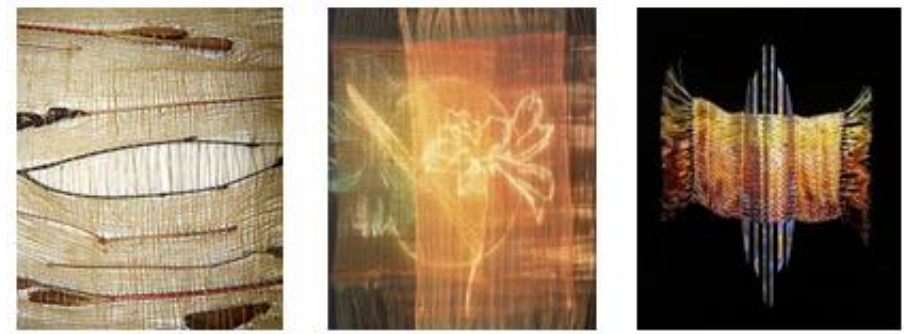

Pictures from 1: 3: Blending textiles and other materials

\subsection{The Third Lecture: (Design)}

\subsubsection{Art Collage Origination:}

Collage or the art of collage scraping arose in China, when paper was invented in about the second century B.C., however, the use of collage remained limited until the tenth century AD, when calligraphers in Japan began using a set of scraps of paper to write on their surface their production of poetry, and was associated The birth and development of modern collage art by the birth of a new wave in the arts called modernity. As for Europe, collage technology emerged in the Middle Ages during the thirteenth century AD, when the Gothic Cathedrals began using paintings made from the leaves of gilded trees, gems and some precious metals In religious paintings, and in the nineteenth century AD collage methods were also used among the collectors of souvenirs, such as their use in decorating photo albums and books, the concept of collage was derived from the word collar invented by Georges Braque and Pablo Picasso in the beginning of the twentieth century AD when the collage became part Important from modern art.

\subsubsection{The Intellectual and Artistic Building of Collage Art: First: Plastic Elements:}

1. Point: It is one of the simplest design elements, it may indicate the place alone, and the point has no dimensions in terms of engineering, that is, it does not have length, width or depth, and most people tend to point the point to a circular shape, and does not display any direction if it is used alone.

2. The line: Is the effect resulting from the movement of a point in a path taken in a particular direction or several successive directions, and it may be defined as a sequence of a group of adjacent points, the formative functions of the lines: The third - the separation of color spaces.

3. Area: It has length and width and has no depth. It is surrounded by lines and defines the outer borders of any size. Space means an elementary flat element that is more complex than point and line.

4. Size: It has length, width, depth, and has no weight, and determines the amount of space occupied by the volume of the vacuum. The primary three-dimensional elements, such as the cube and the triple pyramid, and the ball contain flat shapes that serve as boundaries for the size of the material and separate it from the surrounding medium, and they interfere greatly in determining the body. In its attributes and efficacy affecting perception, the effect of volume is related to the spatial space and the space in which it is present.

5. Texture: Means the sensation resulting from touch and visual perception together. 
The sense of the mind with superficial values and its imagination is a phenomenon sometimes called the visual equivalent of the tactile sense, and the more the artist succeeds in adapting the space and showing its texture, the more the richness of the artistic work. Tactile way.

6. Light and Shade: Opacity and luminosity are among the most used elements in design construction, as they affect scenes with different artistic effects, according to the way light falls on its surface, and opacity and illumination are closely related to the color of the shape and its surface value.

7. Color: Color plays as a constructive element in the works of plastic art. It has a great impact. The strong contact and positive relationship between colors and the organ of vision in man. Reflection of this on the emotions and feelings of the artist is very clear. Whether it is caused by the colored industrial material or by colored light.

\section{Second: Plastic Capabilities:}

1. Rhythm: It is a periodic law that governs kinematic trends and repetitive systems in time sequences that may be similar or different, and it is similar to the time periods that the eye needs to move from one form to another, that is, it arises for the relative relationship between forms.

2. Repetition: It is the use of the optical element more than once, and it is one of the simplest and most common methods, and repetition may be achieved by color, texture, size, shape, or line while its intensity increases, accelerates, or slows down to realize the potential and attractive energy between the parts, which leads to its balance and unity.

3. Continuity: It is the regularity of the relationship between vocabulary without being distracted by the image of the viewer, and it works to track and track the visual elements and vocabulary, despite the large number of direction and movement.

4. Unity: The unity of the structural system in which the various forces of the elements are consistent, the functional integration of its parts, the general color atmosphere of the design, regardless of its different parts in the prestige, value, intensity, unity of expression, psychological impact, and goal. Between them and the standard content you carry.

5. Equilibrium: equilibrium effective forms are balanced, none of which becomes more attractive and blocking without seeing the whole, the balance of color energies with different activities, in stimulating a sense of discretionary movement on the surface or in the depth of design, the balance of kinetic energies expressing change and its causes in design, the balance of the basic axes in Design system.

6. Proportionality: a concept that indicates the importance of relationships between parts of a single entity based on mathematical proportions, and refers to the relationship between the amount of energy and the effectiveness of the function of the parts in the framework of the whole. And proportionality in this way can be returned to a fundamental essence is energy, and considered as a numerical value expressive of the ways in which they exist and the difference in their activities.

7. Vacuum: A flat element alone by its nature cannot contain a vacuum, but if curvature arose a vacuum activity, lines, flats, and blocks all or some of them combine to create a vacuum. 

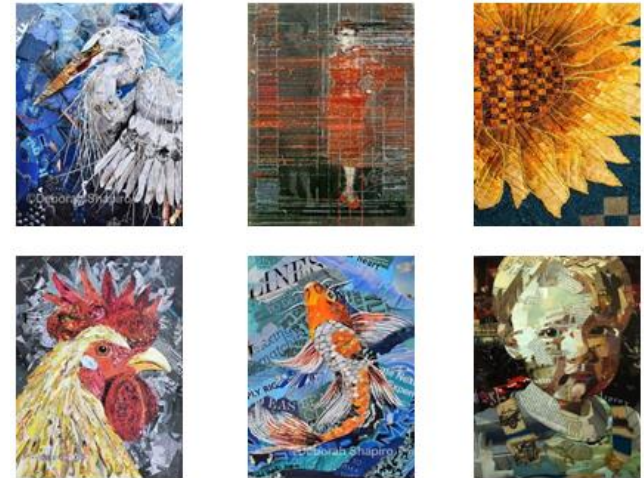

Pictures from 4: 9: The intellectual and artistic building of collage art

\subsection{The Fourth, Fifth, Sixth and Seventh Lectures (Execution)}

The First Entry: Technical and Aesthetic Values Between the Synthesis of Environmental Materials and the Concept of Collage and Its Effect on Weaving:

\section{Synthesis of Raw Material in Art:}

The material or material is the subject of research of any artist, as it realizes his idea financially, and during his artistic practice the artist turns to stones in sculpture, or to colors in photography, and to everything that is located on his eyes in his surroundings, he studies the properties and capabilities of the material to reach a greater understanding that helps him to Adapting it to his art and making it more powerful in expression, because through his studies he knows when to achieve it for a better form and when it is easier and easier to use and what maximum gift can be granted, so it is achieved between him and her with a great familiarity in which the article discloses to him its secrets, and provides him with the size of his living with it, and effort The artist is not limited to his study of the material only in its initial nature It is looking for friendliness with other materials and their success in finding true relationships with each other.

\section{A. Synthesis of Raw Materials in Ancient Egyptian Art:}

The ancient Egyptian artist drew the formulation of the form of symbols from the origins of the appearances of nature surrounding him, as well as religious and mythological beliefs based on the idea of resurrection and eternity. Rather, hieroglyphs became the product of many symbols, for the ancient Egyptian art was the product of eloquent style, "the purpose of the ancient Egyptian artist was not merely to highlight Formal beauty only, but behind his work was a functional significance in a manner consistent with his belief, and for this reason the ancient Egyptian committed himself to show all this to serve him ideas and employ his arts for practical life so that he enriched his life with various artistic creations that are rich in eating raw materials "(9-75), and in Egyptian art an Old style, use synthesis of linen, wool, ores and mineral ores which contributed to show the diversity of artistic works. 


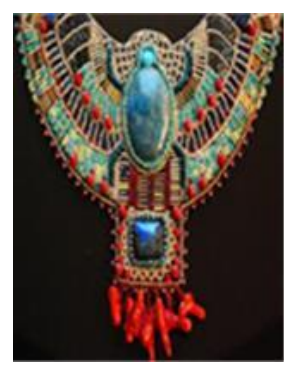

\section{B. Synthesis of Raw Materials in Coptic Art:}

The Coptic artist turned to the symbol, which indicates the consideration within the soul and the spiritual and ideological values that dispense with looking at the world in the hope of asceticism. "Therefore, the Coptic art is considered a true mirror of the complex entity that was composed of Byzantine civilization, as the features and features of Greek and Roman arts consisted of a mixture of varying proportions. Its essence is religious art. "(13-99), and it took from some relationships and forms in ancient civilizations symbols that gave them a new spiritual thought, so he abandoned the worldly anointing and the symbol was associated with the afterlife and virtue, so we find that he was influenced by the ancient Egyptian art style in highlighting sacred personalities through Modify the dimensions according to the spiritual importance of the elements of the depicted subjects, as a symbol for the saints to put a circle or a golden halo around the heads of saints and heroes and around the heads of warriors and women, and use the symbol of the cross for torment and pain, the symbol of the lamb, the fish, the shepherd of Christ and the flying bird a symbol of the Holy Spirit, and reached to Creating new performance methods, such as non-prolonged fevers, which helped to show the diversity of the textile materials.

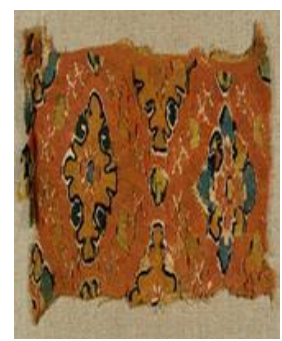

\section{Synthesis of Raw Material in Islamic Art:}

Islamic art arose between the mysticism of the symbol and the spirituality of the Islamic faith, so the Muslim artist established his art through natural symbols and linear and geometrical motifs, relying on its abstraction and modification to not match its realistic forms, so the Islamic artist derived from formations of elements and symbols on which he used his engineering abstractions using geometric forms (such as square and circle) And the Triangle), relying on the engineering and mathematical laws of mind, the Muslim artist used stellar dishes, the basis of which is the circle as a symbol of the continuation of life with an abstract rhythmic system, where the Muslim artist in his 
decorations reflected the infinite rhythm using A mathematical logic of geometry in which to solve the equations of convergence, symmetry and repetition multiplied in form, which generates more complex and deep decorative melodies and reflects the essence of Islamic philosophy with its formative connotations to denote the idea of unlimited, and used Arabic letters and writing contributed to the method of synthesizing the materials to a great artistic degree. "As the silk and reedy textiles industry spread, they produced marigolds, brocade, and reeds in gold and silver" (14-65)

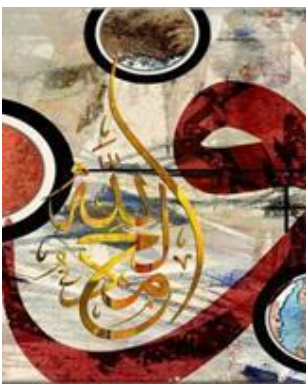

\section{E. Synthesis of Raw Material in Modern Art:}

Scientific and technological progress in the modern era helped change the shape of art, because of the things and assets it did not have before, because each age has its features, which is the disclosure of new materials that did not exist before, and these new materials came as a result of the great technological renaissance. Burlap, ropes, and strings of all kinds to paintings, and we find this in the Cubist, brutal, futuristic, and rudimentary school and .... because of these raw materials they carry, which contribute to achieving variation in texture, color, height, mass, space, and some pioneers in plastic art in Egypt (Munir Kanaan Ahmed Nawar - Farghali Abdul Hafeez - Zainab Sabra).

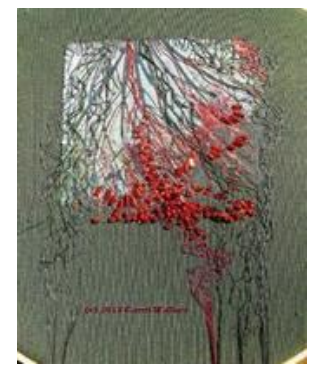

\section{The Role of the Material in the Experiment:}

Sisal: Made of durable and lustrous fibers, it makes some types of walkers and mats for the floor with bright colors, and easy to dye.

Fabric Residues: are what are left of textiles in the form of ribbons of different thicknesses, whether natural or industrial, each according to the material produced from them and used in the Egyptian countryside to make kilims and weaves here has no entry in the colors of the design implemented as the rest of the fabric ribbons are collected without organization or Arrange her. 

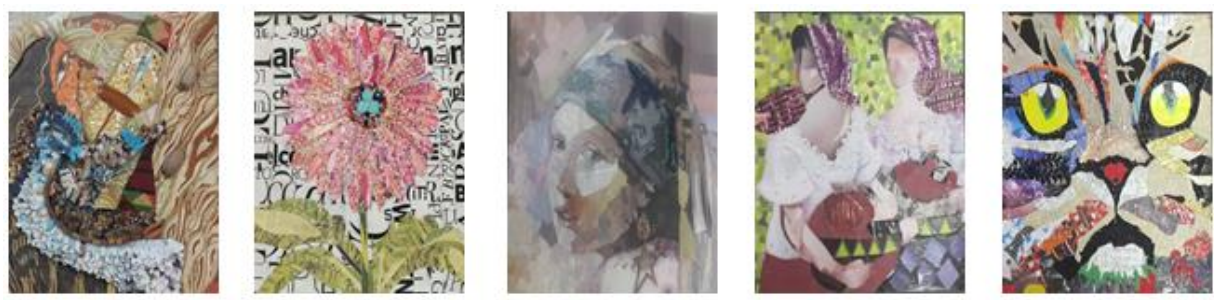

Pictures from 10:14: Examples of student work simulated and collated by famous artists

\subsection{Eighth, Ninth, Tenth, and Eleventh Lectures (Execution) \\ The Second Entry: Plastic Data for the Synthesis Between Raw Material, Printing Effects, Textile and Embroidery:}

\section{Fine Capabilities of Monotype Printing Techniques:}

It is a compound name of two syllables, the first one is mono, meaning one or singular, and the second is a type, and it is a verb in the sense that it is printed by pressing, and so the meaning of the word Monotype is the printing of one copy by pressing, and one of the most important technical methods used is the method (association - thesis). (12-27)

\section{Plastic Delivery Trends:}

1. The Horizontal and Vertical Directions: The strings of warp are strung in the form of two groups, one of which is firmly screwed and the other is horizontally stretched.

2. Stenting Beams: The use of stuttering provides the opportunity to tighten warp threads in more than one direction by using a pillar in the form of a curved line to stretch the threads in the horizontal direction.

3. Obtain the Oblique Direction: It is done by tightening the warp threads in an oblique direction at regular or irregular distances and pulling a group of warp threads in an oblique direction with the tension of another group in the opposite direction

4. The Payment from the Center: In this way, strings of warp are tightened around the ring, which is the center of the emission of the strings inside a frame whose geometric shape changes, and the distance between the strings is uniform or irregular.

5. Two-Position Sealing: Two centers are drawn from each center, the strings of warp are stranded in the form of rays, representing a triangle shape that strings the strands of the first group on one side of the loom and the strands of the second group are on the adjacent side and the strands of the two groups intersect without spun.

6. Closing from More than One Center: To obtain this method, the perforation method can be used, where points are used to tighten the warp threads, including warp threads, and were connected to each other, forming a network of threads. 

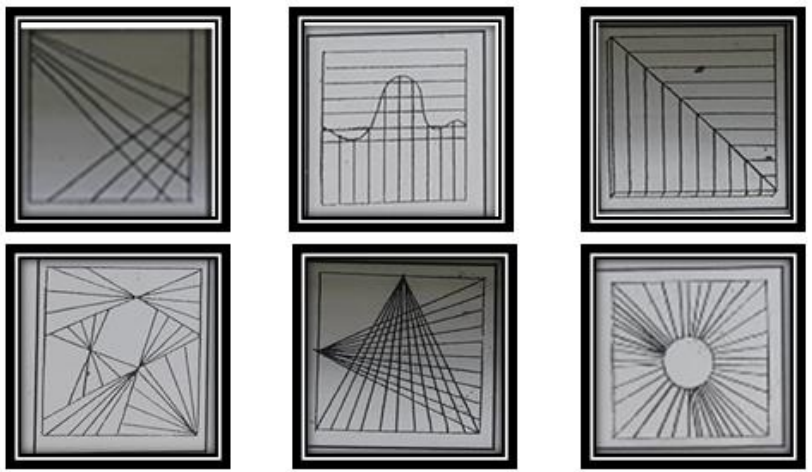

Pictures from 15: 20 Plastic Delivery Trends

\section{The Plastic Potential of Plain Textile:}

Plain textile composition 1/1: It has many forming capabilities that are produced through the extended wefts in the width of the woven. The longitudinal pens are like a shape and its ground, so we see the woven pens once are the shape and the other is the floor, and here the woven color effects occur a reciprocal relationship between the shape and the floor in the textile (5-54)

The $1 / 1$ plain fabric is also characterized by consistency and consistency because each thread in it gives the maximum degree of intertwining to the neighboring threads and produces a more integrated fabric than any other normal fabric (1-20)

\section{Methods of Textile Decoration:}

Embroidery methods: It is a Persian name derived from the Persian word (Leyden style), and it is matched in the English language, embroidery, and in the French language Brodaie. The verb embodies any decoration or decoration applied to a body chosen from a specific fabric.

The style of embroidery developed in the Pharaonic era, where they used different plant designs with flax yarns in different colors, while the Coptic era used the added fabric to decorate the priests' clothes and used the stitching stuff, raw materials, sequins, and beads, whereas in the Islamic era we find pieces of textures that are embroidered with silk threads and used chain, waterfall and plant stitches.

Decorative methods: mesh - Alsumak - free wefts - buttonholes, as for embroidery (chain stitch - Alknafa - blanket - padding - ...).
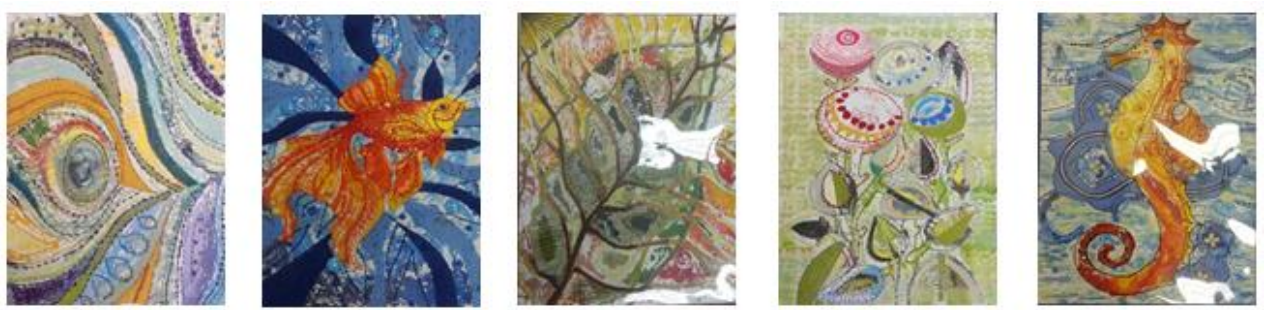

Pictures from 21: 25: Examples of student work Simulation, processing, printing of monotype, fabric, and embroidery 


\subsection{The Twelfth, Thirteenth, Fourteenth and Fifteenth Lectures (Execution)}

The Third Entry: Forming Variables for Geometric Solids:

First: Mass Variables in Geometric Solids:

1. Variables in terms of the type of geometric solids: The shape of the geometrical formation changes according to the shapes and vocabulary component to it, so the formation may be composed of one type of geometric solids, and the formation may combine two or more types of geometric solids.

2. Variables in terms of the distance between the solids: these distances may be uniform and equal through their dependence on a specific numerical sequence, or they may be irregular (randomly formed).

\section{Second: Color Variations in Geometric Figures:}

The color is considered one of the important variables on which the formation of the geometric model is based, the most important of which is the ability to attract attention.

Third: Vacuum Variables in Geometric Solids:

1. The illusive void: it is an apparently empty space that does not have a physical presence, because it occupies an area of flat that has only two dimensions (length and width) and has no depth.

2. Real space: This type is concerned with three-dimensional solids, which are of two types: external space - internal space: permeable and non-permeable.

Fourth: Movement Variables in Geometric Solids:

1. Natural driving forces: air-fire-water-magnetic forces.

2. The viewer: The movement of the viewer in front of the artwork - inside the artwork his participation in the artwork.

3. Industrial driving forces: Electricity - Motor - Timers - Electronic devices that depend on the effect of sound or optical vibrations.

Fifth: The Variables of the Visual Vision Angle in the Formation of the Geometric Figures:

The visibility of the formation of the geometrical models differs according to the variables of the angle of view, and the most important variables are: (the plane of vision the highest level of vision - the bottom of the plane of vision - the vision of the stereoscopic shape in all aspects (front - sides - back).

Sixth: The Variables of Light, Transparency and Opacity in the Formation of Engineering Solids:

1- Transparency is achieved by lights and shadows.

2- Transparency is achieved by forming a light-colored darker.

3- Transparency is achieved by varying the levels of the various geometric figures. 

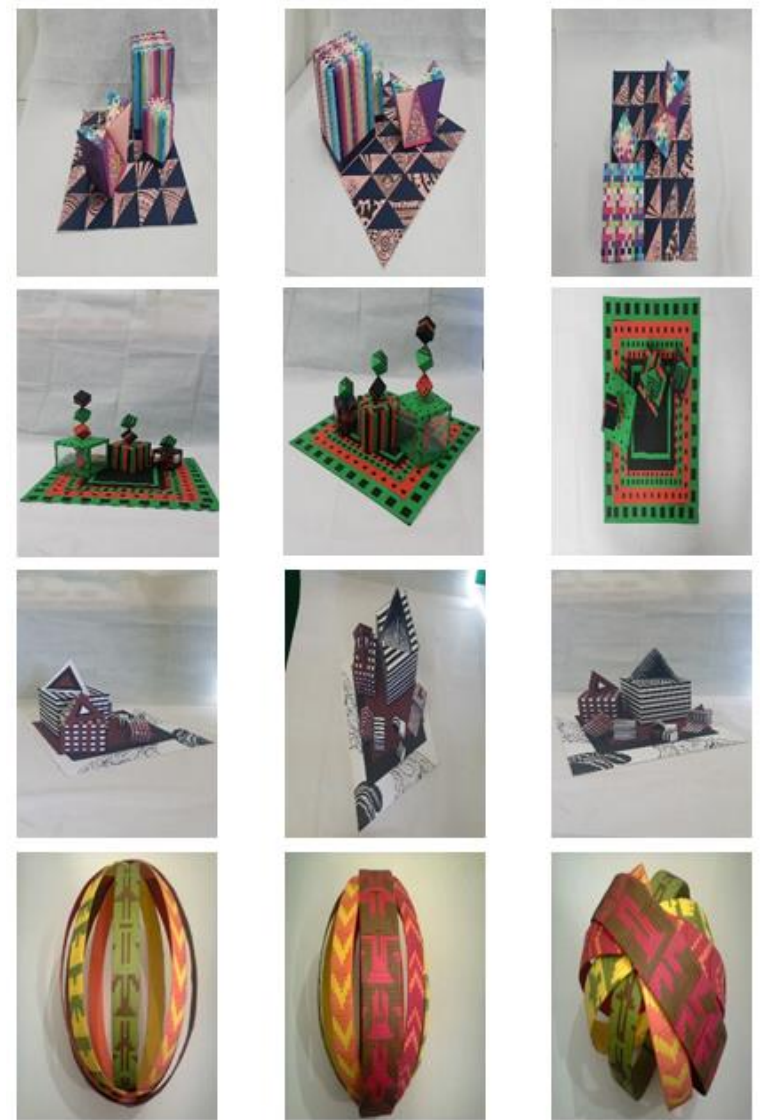

Pictures from 26:29: Models of students' works, textile paper figures

\section{Results}

1. The various contacts of the textile surface (printing - tissue - embroidery - synthesis of paper materials - fabrics - decorative accessories) give harmony and visibility to the surface, which makes its interaction and harmony with the surface clear.

2. Giving an embodiment of the design through the use of printing, weaving and embroidery techniques to give the textile work a third dimension.

3. Merging between techniques helps to develop innovative, creative and skilled thinking through studying the possibility of combining different materials.

\section{Recommendations}

1. Producing periodical publications, catalogs, and magazines that include pictures of students' works and products that help raise the intellectual, artistic, skilled and innovative level.

2. Reviving manual crafts, techniques and skills through training programs and workshops for students. 


\section{References}

Prince Alfons Peter: 1986, formation using simple textile structures, Master Thesis, Faculty of Art Education, Helwan University.

Rehab Taha Hassan Sheridah: 2012, Analysis of the plastic values of engineering shapes in light of the Cubist school as a source for design on mannequin, Ph.D., Faculty of Specific Education, Alexandria University.

Samar Sayed Hassi: 2005, plastic arts as an introduction to the teaching of hand-woven textures to students of the Faculty of Art Education in the light of postmodern arts, Ph.D., College of Art Education, University of Helwan.

Safaa Ali Bayoumi: 2006, the concept of combinations in some modern art schools and its effect on the plastic data of ostrich materials, Ph.D., Faculty of Art Education, Helwan University.

Abdel Rafie Kamel: 1992, the entrance to textile and tapestry technology, Dar Al-Maaref, 2nd floor, Cairo.

Abdul-Ghani Al-Nabawi Al-Shall: 1985, terms in art and art education, architecture of affairs of women, King Saud University.

Ghada Abdel Moneim: 2001, the aesthetic approaches to dealing with plastic media in contemporary handwoven textures, Research Journal in Art Education and the Arts, Volume Three, Faculty of Art Education, Helwan University.

Maher Kamel: Without History, Art and Beauty, The Anglo-Egyptian Library, Cairo.

Mahmoud Al-Nabawi Al-Shall: 2002, plastic arts civilization in ancient Egypt, the Egyptian General Book Authority, Cairo.

Mahmoud Hamed Saleh: 1998, experimental approaches to enrich the field of artistic works in the light of modern artistic trends, Ph.D., Faculty of Art Education, Helwan University.

Munir Al-Baalbaki: 1995, Al-Mawred Dictionary, Dar Al-Alam for Millions, Beirut, Lebanon.

Nadia Ibrahim Shaalan: 2001, introducing creative fields for the synthesis between monotype and fingerprint templates, Master Thesis, Faculty of Art Education, Helwan University.

Nemat Ismail Allam: 1980, Middle Eastern arts in the Hellenistic periods, Christianity, Sassanid, Dar AlMaarif, Cairo.

Nemat Ismail Allam: 1989, Middle Eastern arts in Islamic times, Dar Al-Maarif, Cairo

Herbert Reed: 1986, Art Today, translated by Mohamed Fathi, Gerges Abdo, Dar Al-Maaref, Cairo.

Mitri Elias;1981, Dictionary De Poche, Elias Modern Publishing House, Lerairo.

Peter7Lirda Murray :1959, Dictionary of Art \& Artists, Penguin Books, England.

Runes Dagobest:1964, Encyclopedia of The Art, New York, philosophical, New York. 